\title{
Escherichia coli expression, refolding and characterization of human laforin
}

\author{
Pedro Castanheira ${ }^{\mathrm{a}, *, 1}$, Susana Moreira ${ }^{\mathrm{b}, 1}$, Miguel Gama ${ }^{\mathrm{b}}$, Carlos Faro ${ }^{\mathrm{a}, \mathrm{c}}$ \\ a Biocant, Molecular Biotechnology Unit, Parque Tecnológico de Cantanhede, Núcleo 4, Lote 3, 3060-197 Cantanhede, Portugal \\ ${ }^{\mathrm{b}}$ IBB, Institute for Biotechnology and Bioengineering, Centre of Biological Engineering, Universidade do Minho, Campus de Gualtar, 4710-057 Braga, Portugal \\ ${ }^{\mathrm{c}}$ University of Coimbra, Department of Life Sciences, Apartado 3046, 3001-401 Coimbra, Portugal
}

\section{A R T I C L E I N F O}

\section{Article history:}

Received 19 November 2009

and in revised form 8 February 2010

Available online 10 February 2010

\section{Keywords:}

Laforin

Lafora disease

Inclusion bodies

Refolding

Dual-specificity phosphatase

Carbohydrate binding module

\begin{abstract}
A B S T R A C T
Laforin is a unique human dual-specificity phosphatase as it contains an amino terminal carbohydrate binding module (CBM). Laforin gene mutations lead to Lafora disease, a progressive myoclonus epilepsy with an early fatal issue. Previous attempts to produce recombinant laforin faced various difficulties, namely the appearance of protein inclusion bodies, the contamination with bacterial proteins and a high tendency of the protein to aggregate, despite the use of fusion tags to improve solubility and ease the purification process. In this work, we have expressed human laforin in Escherichia coli in the form of inclusion bodies devoid of any fusion tags. After a rapid dilution refolding step, the protein was purified by two chromatographic steps, yielding 5-7 mg of purified protein per liter of bacterial culture. The purified protein was shown to have the kinetic characteristics of a dual-specificity phosphatase, and a functional carbohydrate binding module.

With this protocol, we were able for the first time, to produce and purify laforin without fusion tags in the amounts traditionally needed for the crystallographic structural studies paving the way to the understanding of the molecular mechanisms of laforin activity and to the development of novel therapies for Lafora disease.
\end{abstract}

(c) 2010 Elsevier Inc. All rights reserved.

\section{Introduction}

Laforin is a human dual-specificity protein phosphatase that contains an N-terminal carbohydrate binding module (CBM) domain and a C-terminal HCXXGXXR(S/T) phosphatase catalytic active site motif [1,2]. The CBM domain encompassing the first 120 amino acids could be aligned with starch binding domains of family CBM20, CAZy database (http://www.cazy.org/fam/ CBM20.html), whose members are also often designated as starch binding domains.

Laforin was found to be involved with Lafora disease, an early onset fatal progressive myoclonus epilepsy with autosomal recessive inheritance [3-6]. Clinically, the disease is characterized by myoclonic seizures and cumulative neurological deterioration, and the appearance of deposits of insoluble hyperphosphorylated glucans exhibiting sparse branching, called Lafora bodies, in the cytoplasm of nearly all cell types [3-5]. Because laforin has a CBM, it was hypothesized that it might be involved in glycogen metabolism. In fact it was shown that the CBM domain of laforin targets the phosphatase domain to glycogen [2] which in turn

\footnotetext{
* Corresponding author. Address: Pedro Castanheira, Biocant, Parque Tecnológico de Cantanhede, Núcleo 4, Lote 3, 3060-197 Cantanhede, Portugal. Fax: +351 231419049.

E-mail address: pedro.castanheira@biocant.pt (P. Castanheira).

1 Both authors contributed equally to this work.
}

can dephosphorylate glycogen [7]. Mutations of laforin that disable the glycogen binding domain also eliminate its ability to dephosphorylate glycogen, leading to excessive phosphorylation of glycogen that was proposed to lead to the aberrant branching of glycogen and the formation of Lafora bodies [7]. The studies that have shown the interaction of laforin with other glycogen synthesis enzymes, such as the glycogen targeting regulatory subunit R5 of protein phosphatase $1[8,9]$, glycogen synthase kinase $3[10]$ and regulatory proteins such as malin, an E3 ubiquitin ligase that targets laforin for degradation [11], helped to explain the formation of Lafora bodies and the demonstration of a crucial role for laforin in glycogen synthesis [12].

While multiple groups have shown that laforin and other glucan phosphatases dephosphorylate phosphoglucans, there is no structure of a glucan phosphatase and little is known about the mechanism whereby they perform this action [13]. Very recently the phosphoglucan interacting regions of laforin were determined [13], but its three-dimensional structure remains elusive. Several groups have attempted to express laforin, and until now only tagged versions of the protein have been described with several groups describing the high tendency of laforin to precipitate, the formation of inclusion bodies (IBs) and the co-precipitation of other proteins, mostly chaperones, even purifying the protein by affinity chromatography [14-17]. Nevertheless, the recombinant forms of laforin have been described to hydrolyze dual-specificity 
phosphatase specific substrates, in a dimerized dependent state [14-17], and to bind and be inhibited by glycogen and related polysaccharides [16-18].

In this paper, we present a novel method to produce high amounts of full-length laforin devoid of fusion tags. The characterization of the purified protein revealed that recombinant laforin is in dimeric state and has similar kinetic and carbohydrate binding properties to the material produced in the previously described purification attempts.

\section{Materials and methods}

The plasmid pET21a(+) containing the cDNA coding for fulllength laforin with a C-terminal hexahistidine tag was a kind gift from Dr. Jack Dixon (U. Michigan, Ann Arbour, Michigan, USA) [2].

\section{Site-directed mutagenesis}

To remove the hexahistidine tag coded by the laforin-his_pET21a(+) construction we have inserted a stop codon at laforin Cterminal by site-directed mutagenesis. For that we have designed the following set of primers:

\section{Laforin-dHis-for: \\ CGTTCTTCTGTGTGTAGCCTGTGAGAGCACCACCACCACCACCAC Laforin-dHis-rev:

GTGGTGGTGGTGGTGGTGCTCTCACAGGCTACACACAGAAGAACG

The mutagenesis was performed using the QuikChange Site-Directed Mutagenesis Kit (Stratagene) according to manufacturer's instructions. The insertion of the TGA stop codon also removed the Xho I restriction endonuclease site that was previously used to clone the laforin cDNA [2], and this change allowed us to identify the positively mutated clones. The positive clones identified were later confirmed by automated DNA sequencing analysis.

\section{Expression, refolding and purification}

The culture of Escherichia coli BL21 star (Invitrogen) transformed with the appropriate expression construct was grown in $1 \mathrm{~L}$ LB (Luria-Bertani) medium with $30 \mu \mathrm{g} / \mathrm{ml}$ ampicillin at $37^{\circ} \mathrm{C}$, $185 \mathrm{rpm}$ in New Brunswick Innova 44R incubator shakers. The expression of laforin was induced by the addition of IPTG into the culture medium at mid-log phase $\left(\mathrm{OD}_{600}=0.6\right)$ to $0.5 \mathrm{mM}$ final concentration. After $3 \mathrm{~h}$, cells were harvested, resuspended in $50 \mathrm{ml}$ of TN buffer ( $50 \mathrm{mM}$ Tris, $150 \mathrm{mM} \mathrm{NaCl}(\mathrm{pH} 7.4)$ ) and lysed by adding lysozyme $(100 \mu \mathrm{g} / \mathrm{ml})$. After freeze and thawing, deoxyribonuclease I $(100 \mu \mathrm{g} / \mathrm{ml})$ and $\mathrm{MgCl}_{2}(100 \mathrm{mM})$ were added and the extract incubated at $4{ }^{\circ} \mathrm{C}$ for $1 \mathrm{~h}$ with occasional stirring. The inclusion bodies were then washed for $3 \mathrm{~h}$ with $1 \mathrm{~L}$ of TN buffer (50 mM Tris, $150 \mathrm{mM} \mathrm{NaCl}$ (pH 7.4)), pelleted at 10,000 $\mathrm{g}$ and then washed again for another $3 \mathrm{~h}$ with $1 \mathrm{~L}$ of TNT buffer $(50 \mathrm{mM}$ Tris, $50 \mathrm{mM} \mathrm{NaCl}(\mathrm{pH} 7.4), 0.1 \%$ Triton X-100 (v/v)) followed by centrifugation at $10,000 \mathrm{~g}$. The pelleted inclusion bodies were then dissolved in $50 \mathrm{ml}$ of $8 \mathrm{M}$ urea buffer ( $8 \mathrm{M}$ urea, $0.1 \mathrm{M}$ Tris, $1 \mathrm{mM}$ glycine, $1 \mathrm{mM}$ EDTA, pH 10.5), with $100 \mathrm{mM} \beta$-mercaptoethanol and were then rapidly diluted (20-fold) at room temperature into $1 \mathrm{~L}$ of $20 \mathrm{mM}$ Tris base, $0.5 \mathrm{mM}$ oxidized/1.25 mM reduced glutathione, $0.5 \mathrm{mM}$ DTT without prior $\mathrm{pH}$ adjustment; the $\mathrm{pH}$ was then slowly adjusted to 8.0 with $6 \mathrm{M} \mathrm{HCl}$ and the solution was kept at cold room until purification.

After 3-4 days to a week period the refolded laforin solution was first concentrated by tangential flow ultrafiltration (Sartocon Slice - Sartorius) to approximately $150 \mathrm{ml}$, followed by a $\mathrm{N}_{2}$ pressurized stirred cell concentrator (Amicon 8200 - Millipore) to $12-15 \mathrm{ml}$. After ultracentrifugation to clarify the solution $\left(100,000 \mathrm{~g}, 20 \mathrm{~min}, 4^{\circ} \mathrm{C}\right)$, the protein was applied to a $320-330 \mathrm{ml}$ bed volume HiLoad 26/60 Superdex 200 prep grade column (Amersham) pre-equilibrated at room temperature with $20 \mathrm{mM}$ Tris, $0.4 \mathrm{M}$ urea, $\mathrm{pH} 8.0$ at $2.0 \mathrm{ml} / \mathrm{min}$. The collected fractions with phosphatase activity were pooled and applied to a Mono Q HR 5/5 (Amersham) column equilibrated with $20 \mathrm{mM}$ Tris, $0.4 \mathrm{M}$ urea, $\mathrm{pH} 8.0$ at $0.75 \mathrm{ml} / \mathrm{min}$. The elution was done by a linear $\mathrm{NaCl}$ gradient from 0 to $0.5 \mathrm{M}$.

\section{SDS-PAGE}

The protein purity was assessed by SDS/PAGE using $12.5 \%$ gels in a BioRad Mini Protean III electrophoresis apparatus according to the method of Laemmli, and stained with Coomassie brilliant blue R-250.

\section{Enzyme assays and kinetics}

During purification the enzyme activity was monitored using $p \mathrm{NPP}^{2}$ at a standard concentration of $10 \mathrm{mM}$ at $30^{\circ} \mathrm{C}$, in $1 \mathrm{ml}$ (total volume) of $50 \mathrm{mM}$ Tris/HCl buffer, $\mathrm{pH}$ 7.2, with a Varian Cary 100 $\mathrm{UV} /$ vis Spectrophotometer, following the increase of $\mathrm{OD}_{410}$ induced by the release of $p$-nitrophenol (with $\varepsilon_{405 \mathrm{~nm}}=18.3 \mathrm{mM}^{-1} \mathrm{~cm}^{-1}$ ) [16]. For kinetic parameter determination the concentration of pNPP varied, while the buffer and temperature conditions were the same. The kinetic parameters determination was also performed using OMFP as substrate under the same conditions used for $p$ NPP. These studies were performed by fluorescence analysis using an Horiba Jobin Yvon Fluoromax-3 fluorometer following the fluorescence emission of the product formed with excitation wavelength set at $485 \mathrm{~nm}$ and emission wavelength at $530 \mathrm{~nm}$. Since OMFP was dissolved in DMSO, the activity assays using OMFP were done in the presence of $10 \%$ DMSO. For determination of the relation between fluorescence units and product concentration, $5 \mathrm{nmol}$ OMFP were hydrolyzed to completion and the fluorescence difference between the non-hydrolyzed substrate and the completely hydrolyzed product were measured.

Protein was quantified by the BCA (Bicinchoninic Acid) Protein Assay (Pierce - Thermo Scientific), using bovine serum albumin as protein standard, according to manufacturer's instructions.

The data were fitted to the Michaelis-Menten equation (Eq. 1) using the software Enzyme Kinetics Module - Sigmaplot (Systat Software Inc.).

$V=k_{\text {cat }}[S] /\left(K_{\mathrm{M}}+[S]\right)$

Testing the effect of glycogen on laforin activity was carried out with $20 \mathrm{nM}$ laforin in the presence of $20 \mu \mathrm{M}$ OMFP in the same conditions described before.

\section{Recombinant protein analysis}

Analytical size exclusion chromatography was performed in AKTA FPLC system (GE/Amersham) using a Superose 12 10/300 GL (GE/Amersham). Laforin $(250 \mu \mathrm{l})$ were applied to the column pre-equilibrated with $20 \mathrm{mM}$ Tris, $0.4 \mathrm{M}$ urea, $150 \mathrm{mM} \mathrm{NaCl}, \mathrm{pH}$ 8.0 at $0.4 \mathrm{ml} / \mathrm{min}$ at room temperature. Column calibration was performed under the manufacturer's instructions using the low molecular weight and the high molecular weight gel filtration calibration kits (GE/Amersham). The protein size was also determined by dynamic light scattering (DLS; Malvern Instruments - Nano Zetasizer ZS with software version 6.01), allowing an estimation

\footnotetext{
${ }^{2}$ Abbreviations used: pNPP, p-nitrophenyl phosphate; OMFP, 3-O-methylfluoresceinyl phosphate.
} 
of the molecular size and weight. The DLS measurements were performed at room temperature, using a protein sample at $0.5 \mathrm{mg} / \mathrm{ml}$.

\section{Adsorption assay}

To evaluate the laforin starch binding capability, adsorption assays using starch were carried out. The purified protein samples $(0.25 \mathrm{mg} / \mathrm{ml})$ were mixed with $50 \mathrm{mg}$ of starch previously washed with $50 \mathrm{mM}$ Tris- $\mathrm{HCl}, 50 \mathrm{mM} \mathrm{NaCl}, \mathrm{pH} 7.4,0.1 \% \quad \beta$-mercaptoethanol buffer, $\mathrm{pH} 7.4$, for $1 \mathrm{~h}$, at $4{ }^{\circ} \mathrm{C}$. Then, the mixture was centrifuged $\left(13,000 \mathrm{rpm}, 10 \mathrm{~min}, 4{ }^{\circ} \mathrm{C}\right)$ and the supernatant was analyzed by SDS-PAGE. The starch was washed out with buffer $(3 \times 0.3 \mathrm{ml})$ until no protein was detected in the supernatant. The recombinant laforin was eluted from starch with $5 \mathrm{mg} / \mathrm{ml}$ glycogen solution $\left(0.3 \mathrm{ml}\right.$, at $4{ }^{\circ} \mathrm{C}$ for $\left.1 \mathrm{~h}\right)$.

\section{Results and discussion}

\section{Protein expression and purification}

The plasmid construction coding for full-length laforin that we received from Dr. Jack Dixon also coded for a C-terminal hexahistidine tag [2], which had been previously associated with problems in protein purification and stability [15-17]. For this reason we decided to introduce a stop codon before the hexahistidine tag coding sequence. This was accomplished by site-directed mutagenesis using QuikChange Site-Directed Mutagenesis Kit (Stratagene).

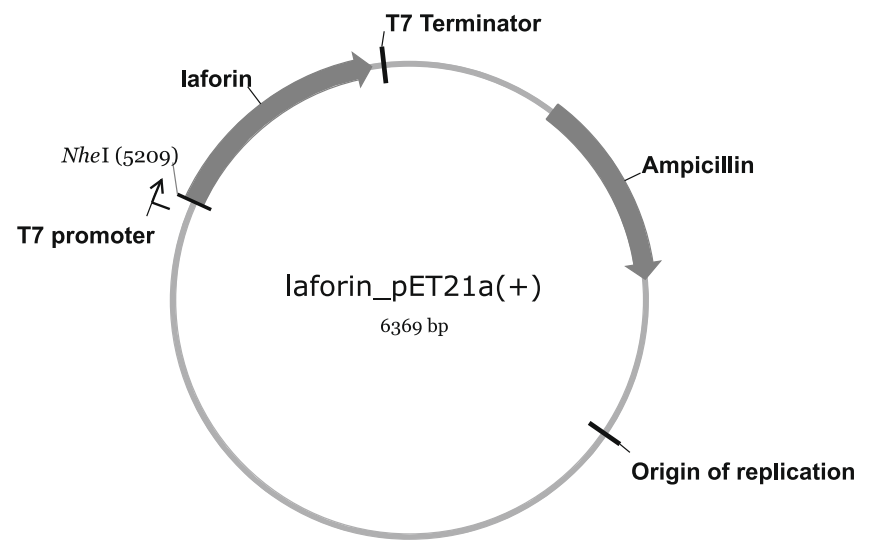

Fig. 1. Construction of laforin cDNA cloned into the expression vector pET21a(+) The cDNA was originally cloned in between Nhe I site and the Xho I site of the multi-cloning site in the pET21a(+) vector without stop codon. We have inserted a stop codon at the end of laforin cDNA, resulting in the loss of Xho I site.
Table 1

Purification Table (from $1 \mathrm{~L}$ culture).

\begin{tabular}{lllllll}
\hline Step & $\begin{array}{l}\text { Volume } \\
(\mathrm{ml})\end{array}$ & $\begin{array}{l}\text { Total } \\
\text { activity } \\
(\mathrm{U})\end{array}$ & $\begin{array}{l}\text { Total } \\
\text { protein } \\
(\mathrm{mg})\end{array}$ & $\begin{array}{l}\text { Specific } \\
\text { activity } \\
(\mathrm{U} / \mathrm{mg})\end{array}$ & $\begin{array}{l}\text { Yield }^{\mathrm{c}} \\
(\%)\end{array}$ & $\begin{array}{l}\text { Purification } \\
\text { factor }\end{array}$ \\
\hline Refolded $^{\mathrm{a}}$ & 7 & 7250 & 39 & 186 & 100 & \\
Superdex & 38 & 5524 & 22 & 251 & 76 & 1.3 \\
Mono Q & 6.5 & 3400 & 7 & 486 & 47 & 2.6 \\
\hline
\end{tabular}

a The starting material was 1 L culture of $E$. coli expressing laforin (weight of wet bacteria: $4.2 \mathrm{~g}$; total protein in bacterial extract: $336 \mathrm{mg}$; weight of wet inclusion bodies: $0.61 \mathrm{~g}$; total protein refolded: $122 \mathrm{mg}$ ).

${ }^{b}$ One Unit of activity was defined as the activity corresponding to the consumption of $1 \mu \mathrm{M}$ substrate ( $p \mathrm{NPP}$ ) in $1 \mathrm{~min}$ at $30^{\circ} \mathrm{C}$.

c Yield was calculated based on recovery of activity.

After the mutagenesis PCR, the positive mutant clones were identified by restriction analysis based on the loss of Xho I site and confirmed by automated DNA sequencing analysis. A diagram of the plasmid construction is presented in Fig. 1.

After a 3-h induction with IPTG, E. coli (BL21 star) cells transformed with laforin-pET21a(+) exhibited a high level of recombinant human full-length laforin expression in the insoluble fraction (Fig. 2C, lane 3). The protein was first purified in the form of inclusion bodies and after a denaturing step with $8 \mathrm{M}$ urea, the refolding was achieved using a protocol already established in our laboratory [19] by rapid diluting the protein into a $\mathrm{Tris}-\mathrm{HCl}$ solution in the presence of reduced and oxidized forms of glutathione, DTT and 2-mercaptoethanol, with the pH slowly adjusted to 8.0. During the refolding step there was some protein precipitation observed by a slight increase in solution turbidity, but the insoluble material was successfully removed by ultracentrifugation prior to the first chromatographic step. The soluble forms of the protein were applied to a Superdex 200 gel filtration column (GE Healthcare) in order to separate the soluble aggregates from the non-aggregated forms of the protein, with the $p N P P a s e$ activity being detected on the second peak of Superdex 200 chromatogram (Fig. 2 A).

The protein was then loaded onto an anion-exchange resin in order to obtain a more homogeneous and concentrated protein. The results in Fig. 2 B show a major peak that proved to be the one with highest activity (data not shown). We have also observed some activity in the adjacent peak, but we think that this might be due to the overlapping of the two protein peaks.

At the end of the purification process from several expression batches we could obtain between 5 and $7 \mathrm{mg}$ of purified active laforin per liter of expression media.

The purification table (Table 1 ) shows that the starting material after refolding was already relatively pure, since the purification factor was only 2.6, which is consistent with the lack of contaminant bands in the SDS-PAGE profile of refolded protein (Fig. $2 \mathrm{C}$,
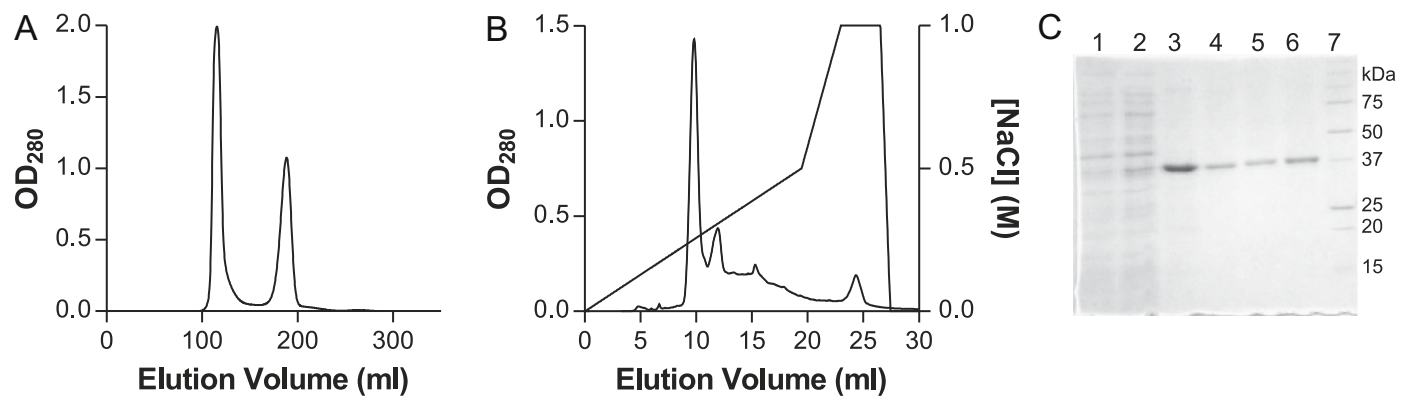

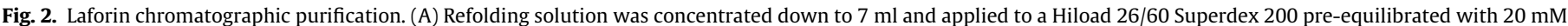

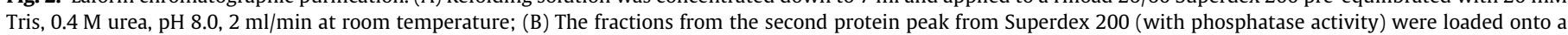

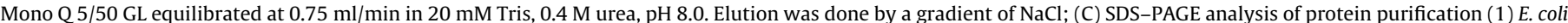

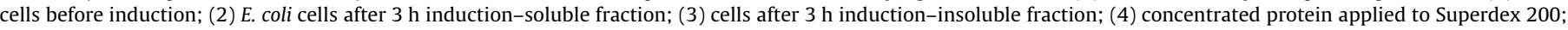
(5) second peak from Superdex 200 applied to Mono Q; (6) Mono Q peak; (7) molecular weight standard. Gel was stained with Coomassie blue. 

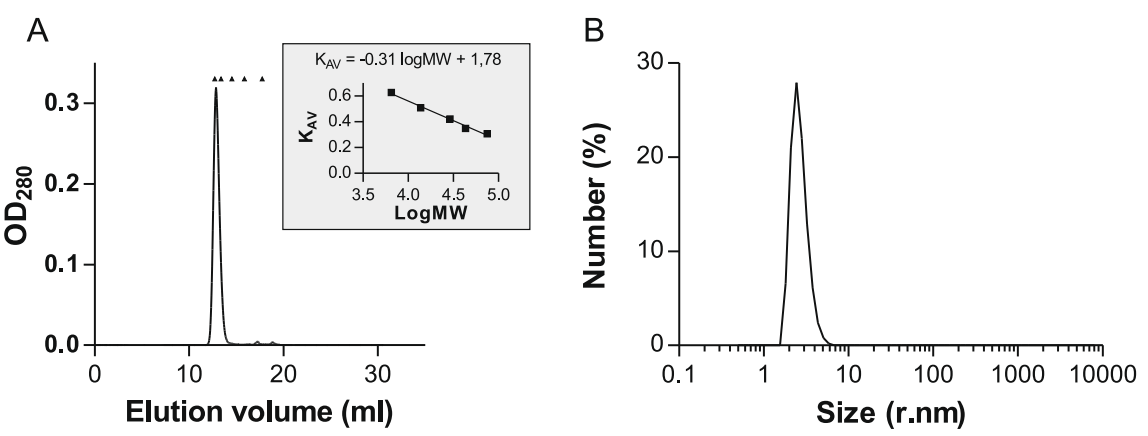

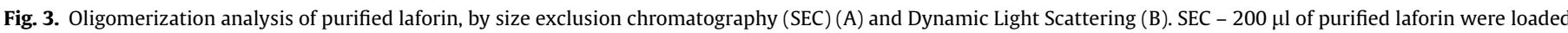

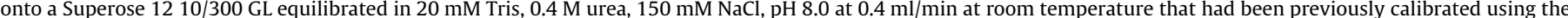

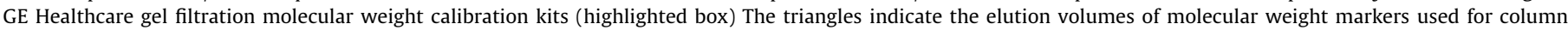

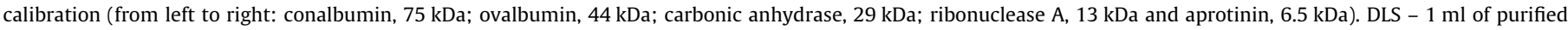
laforin was analysed in a Malvern Zetasizer Nano apparatus. Presented is the size distribution by number result.

lane 3). This is due to the fact that inclusion bodies purification often yield a rather homogeneous and relatively pure preparation [20], which is, together with the high levels of protein production, one of the advantages of producing recombinant protein in the form of inclusion bodies [20].

\section{Laforin oligomerization state}

Since laforin dimerization seems to be critical for its phosphatase activity [15], we have analyzed the oligomerization state of the purified protein either by analytical size exclusion chromatography (SEC) and dynamic light scattering (DLS). The SEC results (Fig. $3 \mathrm{~A}$ ) have shown that the protein is relatively homogeneous in size, with a unique sharp and well defined peak with an elution volume corresponding to a $64 \mathrm{kDa}$ protein, consistent with the dimer state of laforin $(2 \times 37 \mathrm{kDa})$. This result was later confirmed by DLS. The protein was analyzed in both the anion exchange elution buffer (20 mM Tris, $0.4 \mathrm{M}$ urea, $250 \mathrm{mM} \mathrm{NaCl}, \mathrm{pH}$ 8.0) and in $50 \mathrm{mM}$ Tris, $50 \mathrm{mM} \mathrm{NaCl}$, pH 7.4, with similar results. The particles detected had an hydrodynamic radius of $2.81 \mathrm{~nm}$ (Fig. $3 \mathrm{~B}$ ) which, according to the Malvern Zetasizer DLS software should correspond to a globular protein with mass of $76 \pm 16 \mathrm{kDa}$, which is again consistent with the dimer state of laforin.

\section{Phosphatase activity characterization}

The laforin phosphatase activity was characterized using both $p$-nitrophenyl phosphate ( $p$ NPP) [21] and 3-O-methylfluoresceinyl phosphate (OMFP), previously proposed as better substrate for dual-specificity phosphatases than pNPP [16,22]. The kinetic parameters (Table 2) have shown that the non-tagged version of the protein purified in this study had similar properties when compared to the previously published kinetic parameters for GST and His tagged versions of laforin [16], confirming the behavior of laforin as a dual-specificity phosphatase with OMFP as a better substrate than $p N P P$. The $\mathrm{pH}$ profile of laforin phosphatase activity (Fig. $4 \mathrm{~A}$ ) was again in agreement with the literature $[2,16,17,23]$ with the $\mathrm{pH}$ resulting in the maximal activity in the acidic range, around $\mathrm{pH}$ 6.0. We have also looked for the capability of glycogen to inhibit the phosphatase activity of laforin by including increas-

Table 2

Steady state kinetic parameters for laforin phosphatase activity.

\begin{tabular}{|c|c|c|c|c|c|c|}
\hline \multirow[t]{2}{*}{ Enzyme } & \multicolumn{3}{|l|}{$p N P P$} & \multicolumn{3}{|l|}{ OMFP } \\
\hline & $k_{\text {cat }}\left(\mathrm{s}^{-1}\right)$ & $K_{\mathrm{M}}(\mathrm{mM})$ & $k_{\text {cat }} / K_{\mathrm{M}}\left(\mathrm{s}^{-1} \mathrm{mM}^{-1}\right)$ & $k_{\text {cat }}\left(\mathrm{s}^{-1}\right)$ & $K_{\mathrm{M}}(\mathrm{mM})$ & $k_{\text {cat }} / K_{\mathrm{M}}\left(\mathrm{s}^{-1} \mathrm{mM}^{-1}\right)$ \\
\hline Laforin & $0.56 \pm 0.07$ & $8.4 \pm 0.7$ & $0.07 \pm 0.01$ & $7.6 \pm 1.5$ & $0.21 \pm 0.05$ & $36 \pm 11$ \\
\hline GST-pG laforin & $1.1 \pm 0.1$ & $11.4 \pm 3.0$ & $0.10 \pm 0.03$ & $9.5 \pm 2.0$ & $0.26 \pm 0.04$ & $36 \pm 13$ \\
\hline His-laforin & $1.7 \pm 0.2$ & $33 \pm 3$ & $0.051 \pm 0.004$ & $6.5 \pm 1.3$ & $0.75 \pm 0.29$ & $8.7 \pm 5.1$ \\
\hline
\end{tabular}

Comparison with published data for tagged versions of laforin, taken from Ref. [16]. The kinetic parameters were determined with $50 \mathrm{mM}$ Tris/HCl buffer, $\mathrm{pH} 7.2$ at $30{ }^{\circ} \mathrm{C}$.
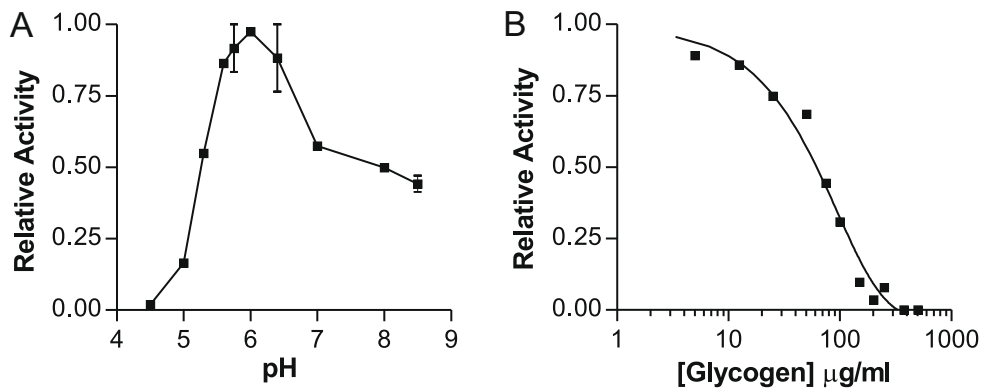

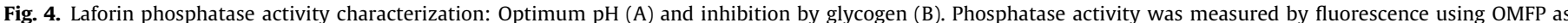

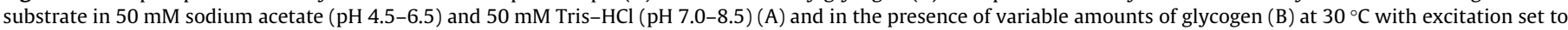
$485 \mathrm{~nm}$ and emission set to $530 \mathrm{~nm}$. 


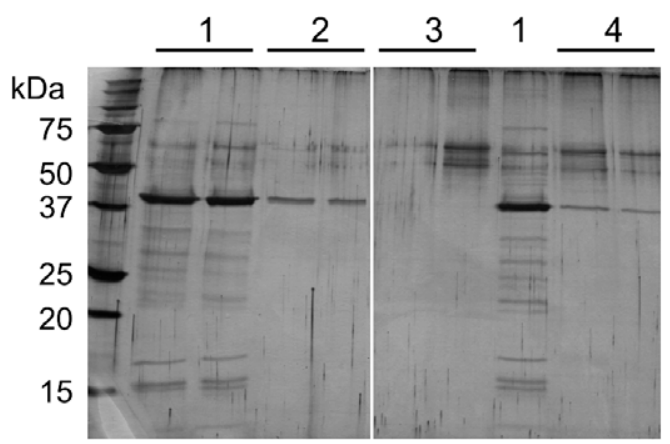

Fig. 5. Starch binding assay. (1) laforin supernatant after centrifugation; (2) supernatant after starch incubation; (3) starch washing supernatant; (4) supernatant after glycogen elution. All steps were done in duplicate. The gel was silver stained.

ing amounts of glycogen into the phosphatase assay. The results presented in (Fig. 4 B) show that laforin, in agreement with previously published results $[16,17]$, is effectively inhibited by glycogen with half the activity being obtained when laforin was incubated with glycogen at concentrations around $50 \mu \mathrm{g} / \mathrm{ml}$. We have also tested the ability of laforin to bind starch by its CBM domain, as observed for other members of CBM20 family. For that purpose we have performed starch adsorption assays, as described under Materials and methods section. The purified laforin (Fig. 5 1) was incubated with starch and after $1 \mathrm{~h}$ the solution was centrifuged. The SDS-PAGE analysis of supernatant revealed that most of the protein was absent in this fraction. This is not due to precipitated protein in the sample as we have centrifuged the protein sample prior to the starch incubation. The subsequent washing steps of the starch precipitate revealed no protein being washed (Fig. 5, lane 3 ), and after glycogen elution step was performed it was clear that it is effective in promoting the elution of laforin from starch (Fig. 5, lane 4) as we could clearly identify the laforin band in the SDS-PAGE. The cluster of bands between about 55 and $65 \mathrm{kDa}$ seen in all the SDS-PAGE lanes, are likely due to keratin contamination in sample and/or in sample buffer. A stronger band might be expected at the glycogen elution step, based on the amount of protein that was bound to the starch moiety, but the relatively faint band resulting from the glycogen elution should be attributed to a stronger binding of laforin towards starch than glycogen, as previously reported [18].

\section{Conclusions}

In this work, we have shown for the first time that full-length human laforin can also be produced in $E$. coli expression systems, in high amounts and devoid of any fusion tags. The characterization showed that we have produced a protein in dimeric state, with kinetic parameters characteristic of dual-specificity phosphatases and with a functional carbohydrate binding module. This protein expression method might be used for the production of the high amounts of protein needed for the determination of three-dimensional structure of laforin, which will contribute to understand the laforin molecular mechanism of action and ultimately contribute to the development of therapies for Lafora disease.

\section{Acknowledgments}

The authors thank Dr. Jack Dixon (U. Michigan, Ann Arbor, Michigan, USA) for providing the laforin.His-pET21a(+) construction. S.M. was recipient of a PhD fellowship from Fundação para a Ciência e a Tecnologia (FCT) - Portuguese Government. Funding from FCT through POCTI program is also acknowledged.

\section{References}

[1] S. Ganesh, K.L. Agarwala, K. Ueda, T. Akagi, K. Shoda, T. Usui, T. Hashikawa, H. Osada, A.V. Delgado-Escueta, K. Yamakawa, Laforin, defective in the progressive myoclonus epilepsy of Lafora type, is a dual-specificity phosphatase associated with polyribosomes, Hum. Mol. Genet. 9 (2000) 2251-2261.

[2] J. Wang, J.A. Stuckey, M.J. Wishart, J.E. Dixon, A unique carbohydrate binding domain targets the lafora disease phosphatase to glycogen, J. Biol. Chem. 277 (2002) 2377-2380.

[3] E.M. Chan, D.M. Andrade, S. Franceschetti, B. Minassian, Progressive myoclonus epilepsies: EPM1, EPM2A, EPM2B, Adv. Neurol. 95 (2005) 47-57.

[4] B.A. Minassian, J.R. Lee, J.A. Herbrick, J. Huizenga, S. Soder, A.J. Mungall, I. Dunham, R. Gardner, C.Y. Fong, S. Carpenter, L. Jardim, P. Satishchandra, E. Andermann, O.C. Snead III, I. Lopes-Cendes, L.C. Tsui, A.V. Delgado-Escueta, G.A. Rouleau, S.W. Scherer, Mutations in a gene encoding a novel protein tyrosine phosphatase cause progressive myoclonus epilepsy, Nat. Genet. 20 (1998) 171-174.

[5] B.A. Minassian, Lafora's disease: towards a clinical, pathologic, and molecular synthesis, Pediatr. Neurol. 25 (2001) 21-29.

[6] G.R. Lafora, B. Glueck, Article on the histopathology of myoclonic epilepsy, Z. Gesamte Neurol. Psychiatrie 6 (1911) 1-14.

[7] V.S. Tagliabracci, J. Turnbull, W. Wang, J.M. Girard, X. Zhao, A.V. Skurat, A.V. Delgado-Escueta, B.A. Minassian, A.A. Depaoli-Roach, P.J. Roach, Laforin is a glycogen phosphatase, deficiency of which leads to elevated phosphorylation of glycogen in vivo, Proc. Natl. Acad. Sci. USA 104 (2007) 19262-19266.

[8] M.E. Fernandez-Sanchez, O. Criado-Garcia, K.E. Heath, B. Garcia-Fojeda, I. Medrano-Fernandez, P. Gomez-Garre, P. Sanz, J.M. Serratosa, C.S. Rodriguez de, Laforin, the dual-phosphatase responsible for Lafora disease, interacts with R5 (PTG), a regulatory subunit of protein phosphatase-1 that enhances glycogen accumulation, Hum. Mol. Genet. 12 (2003) 3161-3171.

[9] C.A. Worby, M.S. Gentry, J.E. Dixon, Malin decreases glycogen accumulation by promoting the degradation of protein targeting to glycogen (PTG), J. Biol. Chem. 283 (2008) 4069-4076.

[10] H. Lohi, L. Ianzano, X.C. Zhao, E.M. Chan, J. Turnbull, S.W. Scherer, C.A. Ackerley, B.A. Minassian, Novel glycogen synthase kinase 3 and ubiquitination pathways in progressive myoclonus epilepsy, Hum. Mol. Genet. 14 (2005) 27272736.

[11] M.S. Gentry, C.A. Worby, J.E. Dixon, Insights into Lafora disease: malin is an E3 ubiquitin ligase that ubiquitinates and promotes the degradation of laforin, Proc. Natl. Acad. Sci. USA 102 (2005) 8501-8506.

[12] D. Vilchez, S. Ros, D. Cifuentes, L. Pujadas, J. Valles, B. Garcia-Fojeda, O. CriadoGarcia, E. Fernandez-Sanchez, I. Medrano-Fernandez, J. Dominguez, M. GarciaRocha, E. Soriano, C.S. Rodriguez de, J.J. Guinovart, Mechanism suppressing glycogen synthesis in neurons and its demise in progressive myoclonus epilepsy, Nat. Neurosci. 10 (2007) 1407-1413.

[13] S. Hsu, Y. Kim, S. Li, E.S. Durrant, R.M. Pace, V.L. Woods, M.S. Gentry, Structural insights into glucan phosphatase dynamics using amide hydrogen-deuterium exchange mass spectrometry, Biochemistry (2009).

[14] M.S. Gentry, R.M. Pace, Conservation of the glucan phosphatase laforin is linked to rates of molecular evolution and the glucan metabolism of the organism, BMC Evol. Biol. 9 (2009) 138.

[15] Y. Liu, Y. Wang, C. Wu, Y. Liu, P. Zheng, Dimerization of laforin is required for its optimal phosphatase activity, regulation of GSK3beta phosphorylation, and Wnt signaling, J. Biol. Chem. 281 (2006) 34768-34774.

[16] J.M. Girard, K.H. Le, F. Lederer, Molecular characterization of laforin, a dualspecificity protein phosphatase implicated in Lafora disease, Biochimie 88 (2006) 1961-1971.

[17] W. Wang, P.J. Roach, Glycogen and related polysaccharides inhibit the laforin dual-specificity protein phosphatase, Biochem. Biophys. Res. Commun. 325 (2004) 726-730.

[18] E.M. Chan, C.A. Ackerley, H. Lohi, L. Ianzano, M.A. Cortez, P. Shannon, S.W. Scherer, B.A. Minassian, Laforin preferentially binds the neurotoxic starch-like polyglucosans, which form in its absence in progressive myoclonus epilepsy, Hum. Mol. Genet. 13 (2004) 1117-1129.

[19] P. Castanheira, B. Samyn, K. Sergeant, J.C. Clemente, B.M. Dunn, E. Pires, B.J. Van, C. Faro, Activation, proteolytic processing, and peptide specificity of recombinant cardosin A, J. Biol. Chem. 280 (2005) 13047-13054.

[20] B. Fahnert, H. Lilie, P. Neubauer, Inclusion bodies: formation and utilisation, Adv. Biochem. Eng. Biotechnol. 89 (2004) 93-142.

[21] J. Montalibet, K.I. Skorey, B.P. Kennedy, Protein tyrosine phosphatase: enzymatic assays, Methods 35 (2005) 2-8.

[22] E.B. Gottlin, X. Xu, D.M. Epstein, S.P. Burke, J.W. Eckstein, D.P. Ballou, J.E. Dixon, Kinetic analysis of the catalytic domain of human cdc25B, J. Biol. Chem. 271 (1996) 27445-27449.

[23] G.H. Peters, S. Branner, K.B. Moller, J.N. Andersen, N.P. Moller, Enzyme kinetic characterization of protein tyrosine phosphatases, Biochimie 85 (2003) 527534. 